\title{
Evaluation of Different Irrigating Solutions on Smear Layer Removal of Primary Root Dentin
}

\author{
${ }^{1}$ Hanan Balto, ${ }^{2}$ Fouad Salama, ${ }^{3}$ Sultan Al-Mofareh, ${ }^{4}$ Faisal Al-Yahya
}

\section{ABSTRACT}

Aim: To evaluate the efficacy of ethanolic extract of Salvadora persica (S. persica) and BioPure MTAD (a mixture of a tetracycline isomer, an acid, and a detergent) in removing the intracanal smear layer of primary teeth.

Materials and methods: The root canal of 40 extracted human primary anterior teeth were cleaned, shaped and grouped into experimental $(n=30)$ and control $(n=10)$. The root canals of the positive $(n=5)$ and the negative control $(n=5)$ were irrigated for 3 minutes with $5 \mathrm{ml}$ of $17 \%$ ethylenediaminetetraacetic acid (EDTA) or saline respectively. The canals in the experimental groups were irrigated for 3 minutes with $5 \mathrm{ml}$ of $1 \mathrm{mg} / \mathrm{ml}$ ethanolic extract of $S$. persica ( $\mathrm{n}$ $=15)$ or BioPure MTAD $(n=15)$ and then flushed with $2 \mathrm{ml}$ of saline. The presence or absence of smear layer at the coronal and middle portion of each canal were examined under a scanning electron microscope (SEM).

Results: A significant difference $(p=0.004)$ in smear layer removal between $S$. persica and MTAD at the middle third of the canal was observed. MTAD solution was as effective as $17 \%$ EDTA in removing the smear layer.

Conclusion: MTAD was significantly more effective in smear layer removal than $S$. persica solution at the middle third of the canal wall.

Clinical significance: Both tested irrigant solutions have the ability to remove the intracanal smear from primary root dentin following cleaning and shaping of the root canal and could be an alternative to EDTA.

Keywords: Laboratory research, S. persica, Primary teeth, Smear layer.

How to cite this article: Balto $\mathrm{H}$, Salama $\mathrm{F}$, Al-Mofareh $\mathrm{S}$, Al-Yahya F. Evaluation of Different Irrigating Solutions on Smear Layer Removal of Primary Root Dentin. J Contemp Dent Pract 2015;16(3):187-191.

\footnotetext{
${ }^{1}$ Department of Restorative Dental Sciences, Division of Endodontics, Dental Caries Research Chair, College of Dentistry, King Saud University, Riyadh, Saudi Arabia

${ }^{2}$ Department of Pediatric Dentistry and Orthodontics, Division of Pediatric Dentistry, College of Dentistry, King Saud University, Riyadh Saudi Arabia

${ }^{3,4}$ College of Dentistry, King Saud University Riyadh Saudi Arabia

Corresponding Author: Hanan Balto, Associate Professor Department of Restorative Dental Sciences, Division of Endodontic, College of Dentistry, King Saud University, Riyadh Saudi Arabia, Phone: +966-14677420, e-mail: h_balto@ yahoo.com
}

\section{Source of support: Nil}

Conflict of interest: None

\section{INTRODUCTION}

The smear layer is an amorphous layer formed by organic and inorganic components generated during cavity and endodontic preparations. ${ }^{1}$ There is controversy concerning whether to remove or retain the smear layer. The use of chelating agents during biomechanical preparation of root canals removes smear layer, thus allowing a better access to irrigant into the dentin tubules for adequate disinfection of the root canals. ${ }^{2}$ Several studies have demonstrated that the smear layer removal is associated with a favorable outcome in primary teeth pulpectomy. ${ }^{3}$ Recently, Barcelos et al ${ }^{4}$ have shown that the outcome for teeth with pulpal necrosis, preoperatory symptoms, or periapical/interradicular radiolucency was significantly improved by removal of the smear layer.

There are a variety of smear layer removal methods, including chemical, ultrasonic, and laser techniques, but none of these effectively removed smear layer throughout the entire canal length. ${ }^{2}$ Among the chemicals ethylenediaminetetraacetic acid (EDTA) solution is most commonly used for smear layer removal. In addition, there are sufficient data recommending the use of sodium hypochlorite $(\mathrm{NaOCl})$ in conjunction with different concentrations of EDTA for effective elimination of smear layer from the root canal system of permanent ${ }^{5}$ and primary teeth. ${ }^{6,7}$

A mixture of a tetracycline isomer, an acid, and a detergent is also believed to be an effective antibacterial irrigant used as a final rinse, during root canal cleaning for removal of smear layer from the instrumented surface of permanent root canal. It is an acidic solution with a $\mathrm{pH}$ of 2.15 and is also capable of removing inorganic substances from the root canal without changing the structure of the dentinal tubules. ${ }^{8,9}$

Salvadora persica (S. persica) is a member of Salvadoraceae family have been traditionally used in Africa, South America, the Middle East, and Asia as an oral hygiene tool for centuries. ${ }^{10,11}$ The efficacy of S. persica is being recognized due to its antimicrobial, ${ }^{10-13}$ anti-inflammatory ${ }^{14}$ and lack of toxicity. ${ }^{15-17}$ Moreover, S. persica extract have also been shown to have smear layer removal capability. ${ }^{18}$ 
There has been no baseline information about the effectiveness of MTAD and S. persica extract on the removal of intra-canal smear layer of primary teeth. Therefore, the aim of this study was to evaluate the efficacy of $1 \mathrm{mg} / \mathrm{ml}$ ethanolic extract of $S$. persica and BioPure MTAD in removing the intracanal smear layer of primary teeth when used as a final rinse.

\section{MATERIALS AND METHODS}

\section{Preparation of Salvadora Persica Extracts}

The roots of $S$. persica were collected from Al-Mukwah, which lies in the Southern region of the Kingdom of Saudi Arabia, in March 2010. The plant was identified by a taxonomist and a voucher specimen (\#1745) was deposited at the herbarium, College of Pharmacy, King Saud University, Riyadh, Saudi Arabia for future reference. The fresh ground roots were extracted with the $10 \%$ water in ethanol then underwent freeze-drying to ensure that the remaining solvent was completely removed. The extract was suspended in dimethyl sulfoxide (DMSO) at a concentration of $100 \mathrm{mg} / \mathrm{ml}$. This was the stock preparation and was kept in a freezer at $-20^{\circ} \mathrm{C}$. Working concentrations of $1 \mathrm{mg} / \mathrm{ml}$ was prepared in sterile physiological saline at a $\mathrm{pH}$ of 7.4.

\section{Specimen Preparation}

Forty extracted human primary anterior teeth which had a single straight root and at least two third of the root was intact were collected and stored in saline throughout the study. The teeth were radiographed from proximal view to ensure that they did not receive any pulp therapy and there was no evidence of calcification. Each tooth was sectioned at the cement-enamel junction (CEJ) using lowspeed carborundum burs under water spray. The roots were further decoronated to obtain a standardized root length of $9 \mathrm{~mm}$.

The working length was measured by deducting $1 \mathrm{~mm}$ from the lengths recorded when the tip of a \#25K-file was visible at the apical end. The canals were enlarged coronally with size 2 and 3 Gates-Glidden burs (Sendoline Perfect Endo, Sweden, Taby). Standard root canal procedure was performed using $\mathrm{K} 3 \mathrm{Ni}-\mathrm{Ti}$ rotary instruments (SybronEndo, Glendora, CA, USA) according to the manufacture instruction until a \#40/0.06 file reached the working length. The canals were irrigated with $2 \mathrm{ml}$ of $1.3 \% \mathrm{NaOCl}$ at each change of instrument. Irrigation was carried out with a $27-\mathrm{G}$ side-vented needle (Monoject; Covidien LP, Deland, FL, USA) attached to a 5-ml syringe inserted at a distance of $2 \mathrm{~mm}$ from the working length without binding. In order to simulate the clinical challenges, a closed system was created by closing the apex of each root with a composite.

After cleaning, shaping and drying of the root canal with absorbent paper points, the roots were randomly divided into experimental $(n=30)$ and control $(n=10)$ groups. The experimental groups were subdivided into two equal groups $(n=15)$ according to the final tested irrigant solutions. The root canals of the positive control $(n=5)$ and the negative control $(n=5)$ were irrigated for 3 minutes with $5 \mathrm{ml}$ of $17 \%$ EDTA or saline respectively. The canals in the experimental groups were irrigated for 3 minutes with $5 \mathrm{ml}$ of $1 \mathrm{mg} / \mathrm{ml}$ ethanolic extract of $S$. persica or BioPure MTAD. The irrigation solutions were delivered in a passive manner using in and out movements via a sterile 27-guage needle that penetrated to within $2 \mathrm{~mm}$ of the working length. The root canals of the experimental groups then underwent a final flush with $2 \mathrm{ml}$ of physiological saline to avoid long-term action of the respective irrigating solutions. The roots were split longitudinally in the buccolingual plane to prepare the samples for scanning electron microscope (SEM) evaluation.

\section{Scanning Electron Microscopy}

Roots were grooved longitudinally on the external surface with a carborundum diamond disk and split into two halves with a chisel. The roots were marked at two levels (coronal and middle thirds) using a marker and processed for SEM examination. Each half was examined individually under SEM (JEOL JSM-636OLV, Tokyo, Japan) at an accelerating voltage of $25 \mathrm{kV}$ using low magnification $(200 \times)$. Then a representative images at the center regions of each third were taken at $1000 \times$ and 2000x. Smear-layer removal was evaluated using the three-point scoring system reported by Torabinejad et al; ${ }^{8}$ a score of (1) indicates the absence of a smear layer on the surface of the root canal and that all tubules are clean and open; a score of (2) indicates a moderate smear layer on the tubules but no smear layer on the surface of the root canal; and a score of (3) indicates a heavy smear layer that covers the root canal surface and the tubules. The scoring procedure was carried out by two blinded examiners after a joint examination of 10 specimens for calibration purposes.

\section{Statistical Analysis}

The reliability of the inter-examiner results was verified by using the kappa test. The score data for the presence or absence of the smear layer were statistically analyzed by Kruskal-Wallis analysis with subsequent pair-wise comparisons of the individual groups. All statistical analyses were set with a significance level of $p<0.05$. 
Table 1: Mean scores of smear layer removal in the experimental and control groups according to the third

\begin{tabular}{llllll}
\hline & $1 \mathrm{mg} / \mathrm{ml}$ & & $17 \%$ & & \\
Levels & S. persica & MTAD & EDTA & Saline & $p$-value \\
\hline Coronal & 39.37 & 35.30 & 26.50 & 73.50 & $<0.05$ \\
Middle & 45.17 & 30.50 & 26.50 & 70.50 & $<0.05$ \\
\hline
\end{tabular}

\section{RESULTS}

The interexaminer reproducibility was excellent for both observers with values equal to 0.86 and 0.097 for MTAD and S. persica respectively. Table 1 shows the mean score ranks at each level. The negative control group had a heavy smear layer and the dentinal tubules were not visible throughout the entire length (Figs $1 \mathrm{~A}$ and $\mathrm{B}$ ). In contrast, the positive controls revealed that the dentinal tubules were open and no smear layer was noted on the surfaces of root canals (Figs 2A and B).

A significant difference $(p=0.004)$ in smear layer removal between $S$. persica and MTAD at the middle third of the canal was observed. MTAD solution was as effective as 17\% EDTA in removing the smear layer from the coronal and middle thirds of the canal wall $(\mathrm{p}=0.367)$. On the other hand, EDTA was significantly more effective than S. persica in removing the smear layer from the coronal $(\mathrm{p}=0.039)$ and middle $(\mathrm{p}=0.014)$ thirds of the specimen. Representative photomicrographs of the experimental group at each third are shown in Figures 3 and 4 .

\section{DISCUSSION}

Various chelating agents have been used in primary teeth for smear layer removal. Citric acid at various concentrations showed to be efficient and most commonly used. ${ }^{6,19}$ In addition, the combination of $2.5 \% \mathrm{NaOCl}$ and $14 \%$ EDTA have also showed to be an effective method for removal of smear layer from root third of primary teeth. ${ }^{20}$

Many chemical substances have already been recognized as efficient for smear layer removal in permanent teeth; however, their effects on primary dentition have not yet evaluated. Considering the anatomical, histological and chemical differences between permanent and primary dentitions results obtained in permanent teeth cannot be transposed to primary teeth. Therefore, the present study was carried out to evaluate the efficacy of 1 $\mathrm{mg} / \mathrm{ml}$ of ethanolic S. persica extract and BioPure MTAD in removing the intracanal smear layer of primary teeth.

In this study, an ethanolic S. persica extract was used due to its significant antimicrobial effect against aerobic and anaerobic bacteria when used as a root canal irrigant. ${ }^{21,22}$
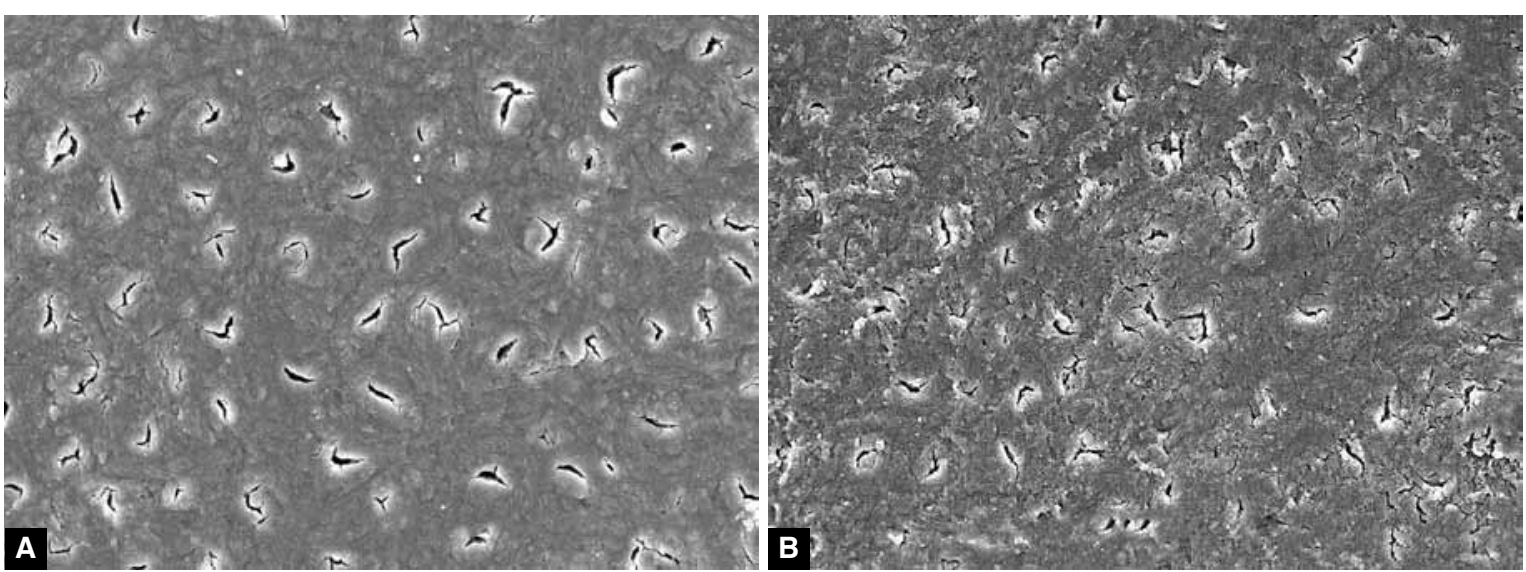

Figs 1A and B: The effect of irrigating with $5 \mathrm{ml}$ of saline for 3 minutes: atypical amorphous smear layer is observed throughout the entire length of the root canal: the coronal $(A)$ and middle $(B)$ thirds (2000x)

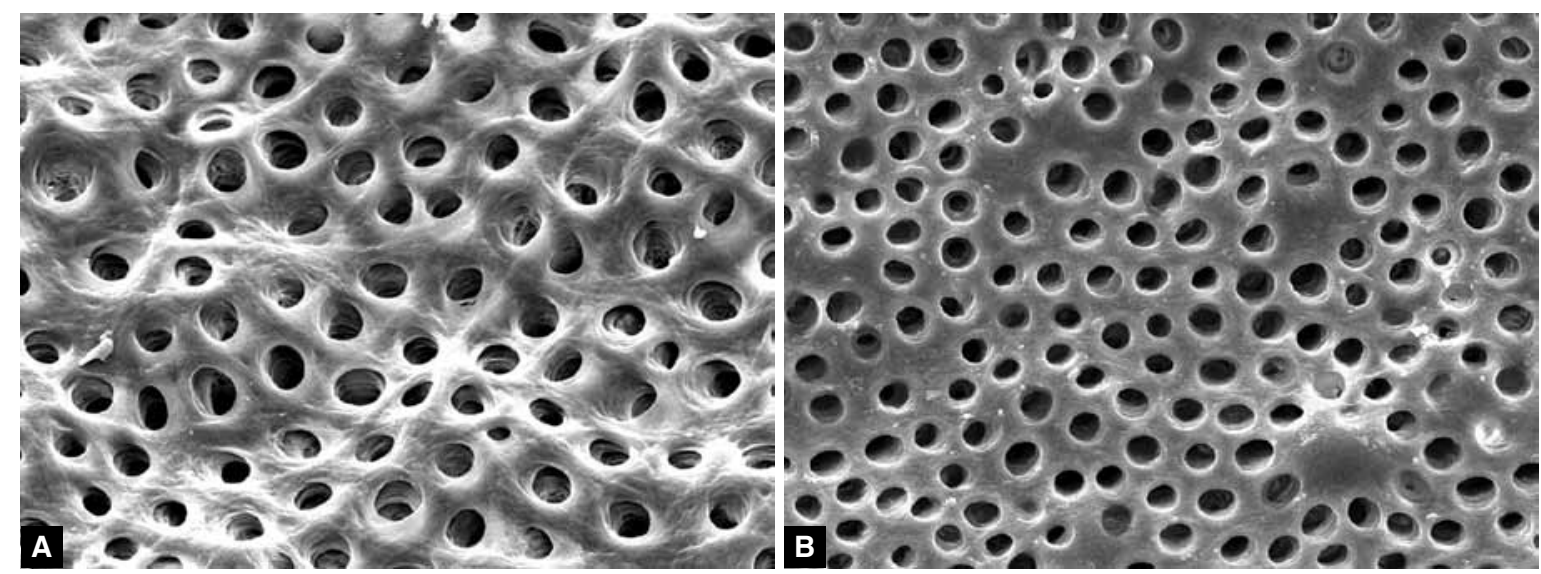

Figs 2A and B: The effect of irrigating with 17\% ethylenediaminet etraacetic acid for 3 minutes; the smear layer is completely removed and all of the tubule openings are clearly visible on the coronal (A) and middle (B) thirds (2000x) 


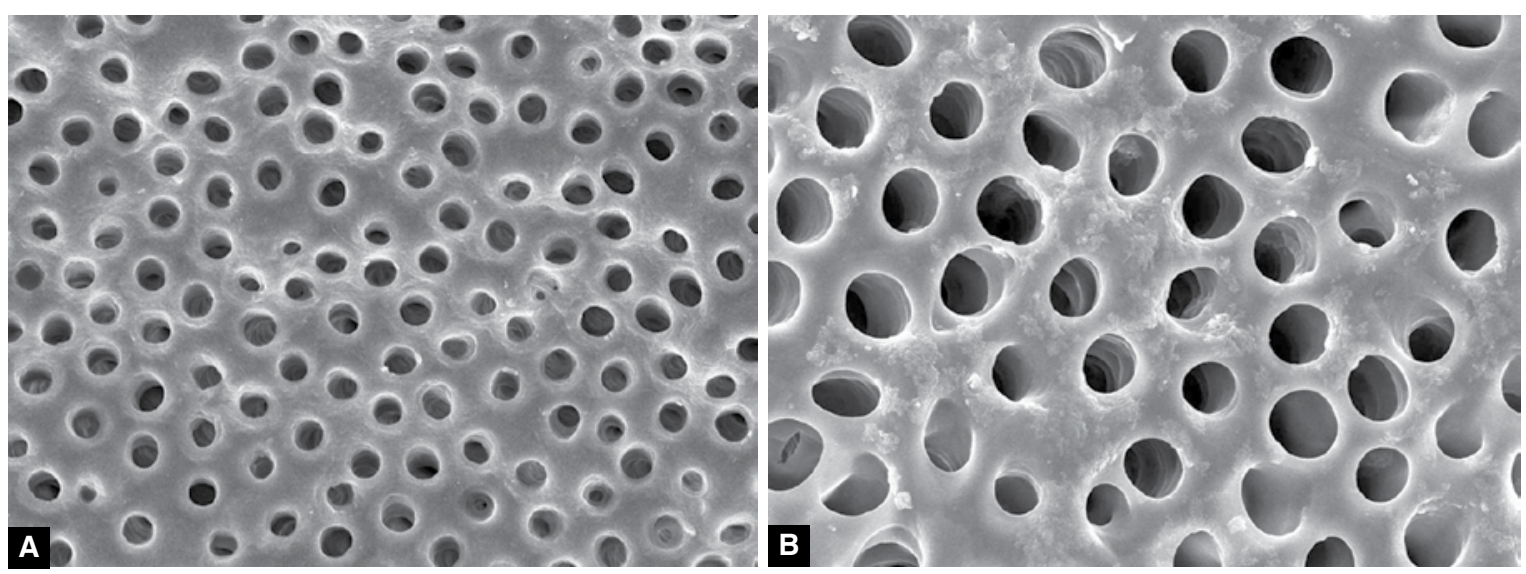

Figs $3 A$ and B: The effect of irrigating with MTAD for 3 minutes; the smear layer is completely removed and all of the tubule openings are clearly visible on the coronal (A) and middle (B) thirds (2000x)
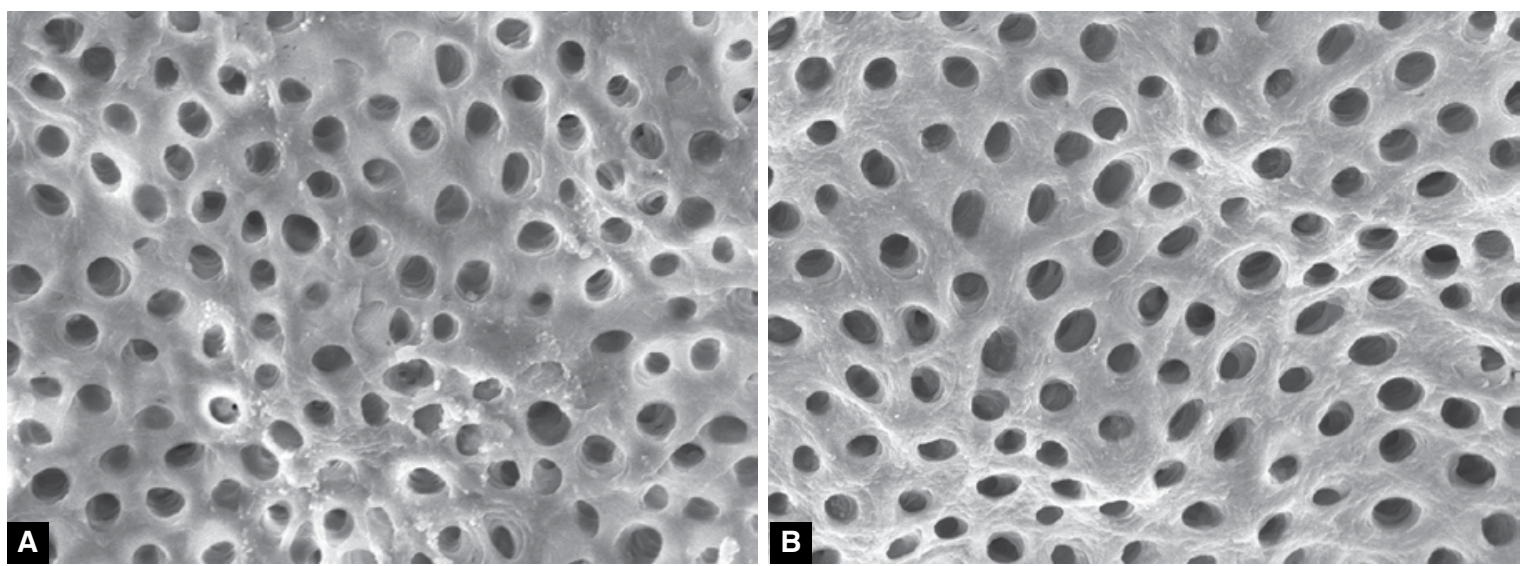

Figs 4A and B: The effect of irrigating with a $1 \mathrm{mg} / \mathrm{ml}$ Salvadora persica solution for 3 minutes; the smear layer is completely removed and all of the tubule openings are clearly visible on the coronal (A) and middle (B) thirds (2000x)

The accepted application time of the chelating solution, as supported by the literature, is between 1 and 5 minutes; ${ }^{23}$ thus irrigation for 3 minutes was adopted for this study. Because of the difficulty of obtaining primary teeth with fully formed roots, this study assessed smear layer removal at the coronal and middle thirds of these teeth. The root canals in this study were cleaned and shaped using rotary files, although no differences were found for cleaning capacity between hand and rotary files, the reduction of cleaning time by the rotary technique is considered a relevant clinical factor for endodontic treatment in pediatric dentistry. ${ }^{24}$

The result of this study showed that MTAD was as effective as $17 \%$ EDTA in removing the smear layer from the coronal and middle thirds of the canal wall. This finding is consistent with others. ${ }^{8,25}$ Both MTAD and S. persica extracts were effective in removing the smear layer from the coronal third of the root canal wall. Although there was a significant difference in smearlayer removal between MTAD and S. persica at the middle third of the canal wall, $1 \mathrm{mg} / \mathrm{ml}$ of $S$. persica was able to partially remove the smear layer from the middle third of the root canal. Such finding is consistent with Balto et $\mathrm{al}^{18}$ The ability of $S$. persica to remove the smear layer is nearly consistent with the findings of Babay and Almas ${ }^{26}$ who observed that alcoholic extract of $S$. persica resulted in the disappearance of the smear layer, although the modes of application, exposure times and sample preparation were different. The ability of $S$. persica to remove the smear layer may be attributed to its acids content, which may react with calcium in the dentin and act as a chelating agent. Additionally, this ability may be due to the neutral $\mathrm{pH}$ of the extract $(\mathrm{pH}=7.4)$ as etching at neutral $\mathrm{pH}$ is equal if not more efficient than with the agents at low $\mathrm{pH}$ in exposing collagen fibrils on dentin surfaces. ${ }^{27}$

Based on previous findings ${ }^{11-18}$ and the current results, a S. persica extract has the potential to be used as an irrigant solution due to its antibacterial, anti-inflammatory, lack of toxicity, and chelating effects. Whilst the current data looks promising, further studies are recommended to provide results that could justify the clinical application of S. persica extract in pediatric dentistry.

\section{CONCLUSION}

Within the limitations of this in vitro study, Bio-pure MTAD was significantly more effective than the $1 \mathrm{mg} / \mathrm{ml}$ ethanolic $S$. persica extract at the middle third. Furthermore, MTAD was as effective as 17\% EDTA in 
removing the smear layer from the coronal and middle thirds of the canal wall of primary teeth.

\section{CLINICAL SIGNIFICANCE}

Both tested irrigant solutions have the ability to remove the intracanal smear from primary root dentin following cleaning and shaping of the root canal and could be an alternative to EDTA.

\section{ACKNOWLEDGMENT}

This study was registered in the College of Dentistry Research Center, King Saud University (NF 2383) and conducted in collaboration with Dental Caries Research Chair. The authors express their appreciation to $\mathrm{Mr}$ Nasser Al Moflehi for his statistical contribution.

\section{REFERENCES}

1. McComb D, Smith D. A preliminary scanning electron microscopic study of root canals after endodontic procedures. J Endod 1975;1:238-242.

2. Violich DR, Chandler NP. The smear layer in endodontics: a review. Int Endod J 2010;43:2-15.

3. Tannure PN, Azevedo CP, Barcelos R, Gleiser R, Primo LG. Long-term outcomes of primary tooth pulpectomy with and without smear layer removal: a randomized split-mouth clinical trial. Pediatr Dent 2011;33:316-320.

4. Barcelos R, Tannure PN, Gleiser R, Luiz RR, Primo LG. The influence of smear layer removal on primary tooth pulpectomy outcome: a 24-month, double-blind, randomized, and controlled clinical trial evaluation. Int J Paediatr Dent 2012;22:369-381.

5. Baumgartner JC, Mader CL. A scanning electron microscopic evaluation of four root canal irrigation regimens. J Endod 1987;13:147-157.

6. Salama FS, Abdelmegid FY. Six percent citric acid better than hydrogen peroxide in removing smear layer: an in vitro pilot study. Pediatr Dent 1994;16:424-426.

7. Barkhordar RA, Watanabe LG, Marshall GW, Hussain MZ. Removal of intracanal smear by doxycycline in vitro. Oral Surg Oral Med Oral Pathol Oral Radiol Endod 1997;84:420-423.

8. Torabinejad M, Cho Y, Khademi AA, Bakland LK, Shabahang $\mathrm{S}$. The effect of various concentrations of sodium hypochlorite on the ability of MTAD to remove the smear layer. J Endod 2003;29:233-239.

9. Lotfi M, Vosoughhosseini S, Saghiri MA, Zand V, Ranjkesh B, Ghasemi N. Effect of MTAD as a final rinse on removal of smear layer in ten-minute preparation time. J Endod 2012; 38:1391-1394.

10. Noumi E, Snoussi M, Hajlaoui H, Valentin E, Bakhrouf A. Antifungal properties of Salvadora persica and Juglansregia L. extracts against oral Candida strains. Eur J Clin Microbiol Infect Dis 2010;29:81-88.

11. Sofrata AH, Claesson RL, Lingström PK, Gustafsson AK. Strong antibacterial effect of miswak against oral microorganisms associated with periodontitis and caries. J Periodontol 2008;79:1474-1479.

12. Al lafi $\mathrm{T}, \mathrm{Ababneh}$. The effect of the extract of the miswak (chewing sticks) used in Jordan and the Middle East on oral bacteria. Int Dent J 1995;45:218-222.

13. Al-Sohaibani S, Murugan K. Anti-biofilm activity of Salvadora persica on cariogenic isolates of Streptococcus mutans: in vitro and molecular docking studies. Biofouling 2012;28:29-38.

14. Ibrahim AY, El-Gengaihi SE, Motawea HM, Sleem AM, Anti-inflammatory activity of Salvadora persica L against carrageenan induced paw oedema in rat relevant to inflammatory cytokines. Not Sci Biol 2011;3:22-28.

15. Balto H, Al-Manei K, Bin-Mohareb T, Shakoor Z, Al-Hadlaq S. Cytotoxic effect of Salvadora persica extracts on human gingival fibroblast cells. Saudi Med J 2014;35:810-815.

16. Darmani H, Nusayr T, Al-Hiyasat AS. Effects of extracts of miswak and derum on proliferation of Balb/C 3T3 fibroblasts and viability of cariogenic bacteria. Int J Dent Hyg 2006;4: 62-66.

17. Ibrahim AY, El-Gengaihi SE. Safety profile of meswak root extract on liver, kidney, sexual hormones and hematological parameters of rats. Not Sci Biol 2012;4:18-23.

18. Balto H, Ghandourah B, Al-Sulaiman H. The efficacy of Salvadora persica extract in the elimination of intracanal smear layer: SEM study. Saudi Dent J 2012;24:71-77.

19. Gotze GR, Cunha CB, Primo LS, Maia LC. Effect of the sodium hypochlorite and citric acid association on smear layer removal of primary molars. Braz Oral Res 2005;19:261-266.

20. Nelson Filho P, Leite Gde A, Fernandes PM, da Silva RA, Rueda JC. Efficacy of Smear Clear and ethylenediaminetetraacetic acid for smear layer removal in primary teeth. J Dent Child 2009;76:74-77.

21. Al-Sabawi NA, Abdal AK, Taha MY. The antimicrobial activity of Salvadora persica (Miswak-Siwak) solution as root canal irrigant (A comparative study). J Pure Appl Sci 2007;4: 69-91.

22. Balto H, Al-Howiriny T, Al-Somaily A et al. Screening for the antimicrobial activity of Salvadora persica extracts against Enterococcus faecalis and Candida albicans. Int phytomed 2013;5:486-92.

23. Yamada RS, Armas A, Goldman M, Lin PS. A scanning electron microscopic comparison of a high volume final flush with several irrigating solutions: Part 3. J Endod 1983; 9:137-142.

24. Silva LA, Leonardo MR, Nelson-Filho P, Tanomaru JM. Comparison of rotary and manual instrumentation techniques on cleaning capacity and instrumentation time in deciduous molars. J Dent Child 2004;71:45-47.

25. Mancini M, Armellin E, Casaglia A, Cerroni L, Cianconi L. A comparative study of smear layer removal and erosion in apical intraradicular dentine with three irrigating solutions: a scanning electron microscopy evaluation. J Endod 2009; 35:900-903.

26. Babay N, Almas K. Effect of miswak extract on healthy human dentin: an in vitro study. Saudi Dent J 1999;11:46-52.

27. Blomlof J, Lindskog S. Root surface texture and early cell and tissue colonization after different etching modalities. Eur J Oral Sci 1995;103:17-24. 